\title{
Dinâmica da Vegetação Arbórea em Floresta Ombrófila Mista Montana Antropizada
}

\author{
Patrikk John Martins ${ }^{1}$, Joelmir Augustinho Mazon ${ }^{1}$, Laís Martinkoski ${ }^{1}$, \\ Cristiane Carla Benin ${ }^{1}$, Luciano Farinha Watzlawick ${ }^{1}$
}

${ }^{1}$ Departamento de Agronomia, Universidade Estadual do Centro Oeste - UNICENTRO, Guarapuava/PR, Brasil

\begin{abstract}
RESUMO
As mudanças na composição florística, na estrutura fitossociológica e os processos dinâmicos do crescimento: ingresso, mortalidade e incremento foram estudados no período de 2007 e 2009 em todos os indivíduos arbóreos com DAP $\geq 5 \mathrm{~cm}$ em um fragmento de Floresta Ombrófila Mista Montana em Boa Ventura do São Roque, no Paraná, Brasil. Os resultados apontaram a ocorrência de 2596 ind.ha-1, 25 famílias, 40 gêneros e 45 espécies, em 2007, ao ponto que, no levantamento realizado em 2009, computaram-se 2558 ind.ha-1, 27 famílias, 41 gêneros e 47 espécies, sendo Matayba elaeagnoides Radlk. a espécie mais importante nos dois levantamentos. A floresta apresentou mortalidade de $0,41 \%$ ao ano e ingresso de $1,75 \%$ ao ano de modo que a dinâmica se produz de forma gradativa, com um incremento médio anual de $0,328 \mathrm{~cm}$.ano- 1 . Com base nos parâmetros avaliados, conclui-se que o fragmento se encontra em processo de regeneração.
\end{abstract}

Palavras-chave: floresta com araucária, crescimento, fitossociologia.

\section{Arboreal Vegetation Dynamics in an Anthropized Montane Araucaria Forest}

\begin{abstract}
Changes in floristic composition, phytosociological structure and dynamic processes like ingrowth, mortality and diameter increment were studied between 2007 and 2009 in all trees with DBH $\geq 5 \mathrm{~cm}$ in a fragment of Montane Araucaria Forest in Boa Ventura do São Roque, Paraná, Brazil. The analyses showed the occurrence 2596 ind.ha-1, 25 families, 40 genera and 45 species, while in the survey conducted in 2009, 2558 indivuals.ha-1, 27 families, 41 genera and 47 species were registered, with Matayba elaeagnoides Radlk. being the most important species in both surveys. The forest fragment showed a mortality rate of $0.41 \%$ per year and recruitment of $1.75 \%$ per year. This indicates that the dynamics take place in a gradual manner, with a mean annual increment (MAI) of $0.328 \mathrm{~cm}$.year- 1 . Based on the evaluated parameters, it follows that the fragment is in process of regeneration.
\end{abstract}

Keywords: araucaria forest, growth, phytosociology.

\section{INTRODUÇÃO}

A Floresta Ombrófila Mista (FOM), ou Floresta com Araucária, é uma unidade fitoecológica pertencente ao domínio do Bioma Mata Atlântica que ocupava originalmente uma área de cerca de $175 \mathrm{mil} \mathrm{km}^{2}$ de extensão. Sua ocorrência se dá principalmente na
Região Sul, no Planalto Meridional Brasileiro, local de seu "clímax climático", existindo também em alguns fragmentos sobre altitudes superiores a $1.000 \mathrm{~m}$ s.n.m., nos estados de São Paulo, Minas Gerais e Rio de Janeiro (Castella \& Britez, 2004; IBGE, 2012). 
A FOM é caracterizada floristicamente pela coexistência de vegetação de origens tropical e subtropical, com presença de gêneros de Coniferales e Laurales, em zona climática caracteristicamente pluvial, com chuvas bem distribuídas ao longo do ano, onde domina a Araucaria angustifolia (Bertol.) Kuntze (Araucariaceae), espécie gregária de alto valor econômico e paisagístico e de padrões fitofisionômicos peculiares (Roderjan et al., 2002).

Essa formação florestal sofreu grande fragmentação no século XX, devido à intensidade da exploração madeireira, principal atividade econômica no Sul do Brasil, em especial no Paraná, nesse período. Desmatamentos e queimadas, substituição da vegetação por pastagens e agricultura, plantios homogêneos com espécies exóticas e ampliação das zonas urbanas que se sucederam também contribuíram sobremaneira para a redução das áreas de florestas originais. Até meados dos anos 2000, a cobertura florestal restante era de aproximadamente 0,7\% da área original (Medeiros et al., 2005).

Com a recorrente perda de áreas florestais e, consequentemente, de sua biodiversidade, o estudo sobre as composições florística e fitossociológica das florestas é de grande importância por oferecer subsídios que auxiliam no entendimento da estrutura dinâmica por meio de parâmetros sucessionais, climáticos, edáficos e antrópicos em uma floresta, imprescindíveis para o manejo e a regeneração das diferentes comunidades vegetais.

A dinâmica sucessional em florestas pode ser caracterizada, principalmente, pelas mudanças na flora e na fauna decorrentes em determinado período. Em tese, a florística e a dinâmica sucessional podem ser mensuradas pela entrada (ingresso), saída (mortalidade) e crescimento das espécies que participam da estrutura florestal. As mudanças florísticas provocadas pela mortalidade e pelo ingresso de plantas podem ser decorrentes de diversos fatores do meio (Whitmore, 1983).

De acordo com Moscovich (2006), o estudo da dinâmica entremostra-se com um conjunto de interações de grande complexidade pela multiplicidade dos fatores nela incluídos. Para o autor, a influência dos fatores físicos do ambiente, em sua infinita quantidade de combinações e permutações de temperatura, luz, propriedades do solo, nutrientes edáficos e umidade, torna-se de difícil compreensão.
Esses fatores são importantes para a dinâmica de ecossistemas florestais, pois geram heterogeneidade ambiental e contribuem para o aumento da diversidade das espécies, ou, ainda, são bases para a reprodução, ingressos, espacialização e partilha de recursos.

Portanto, estudar a dinâmica de uma floresta é importante para conhecer o comportamento dela, ajudando a explicar sua sinecologia, a fim de que seja feito um aproveitamento racional, garantindo a sobrevivência das florestas naturais. Logo, o presente estudo tem como objetivo analisar a dinâmica da estrutura fitossociológica e o crescimento de em um fragmento de Floresta Ombrófila Mista Montana localizada no município de Boa Ventura do São Roque (PR), em um período de dois anos.

\section{MATERIAL E MÉTODOS}

O estudo foi realizado em uma área de floresta natural localizada no município de Boa Ventura de São Roque (PR), região central do estado (Figura 1). A vegetação natural nessa região é descrita como Floresta Ombrófila Mista Montana, cuja ocorrência se dá entre $400 \mathrm{~m}$ e $1.000 \mathrm{~m}$ de altitude, ocupando quase inteiramente o planalto acima de $500 \mathrm{~m}$ nos três estados do Sul, conforme o IBGE (2012) e, mais especificamente, de acordo com Leite (1994), entre 500 e 800 m no estado do Paraná.

Os solos da região de estudo são classificados predominantemente como Latossolos (EMBRAPA, 2006). De acordo com a classificação de Köppen-Geiger, o clima da região é classificado como $C f b$, sem estação seca definida e com verões frescos. As chuvas são abundantes e distribuídas entre os meses do ano, com uma média próxima a $2.000 \mathrm{~mm}$ anuais e, deste modo, não se distingue um período seco (Thomaz \& Vestena, 2003).

A área estudada sofreu forte exploração florestal no passado, ocorrendo a retirada dos indivíduos arbóreos com maior valor econômico e posterior atividade pastoril sob a floresta remanescente. Porém, a área deixou de ser explorada economicamente há pouco mais de 17 anos até a data de realização do estudo.

Para o levantamento florístico e a avaliação da dinâmica florestal, foi instalada uma unidade amostral permanente com $5.000 \mathrm{~m}^{2}(50 \mathrm{~m} \times 100 \mathrm{~m})$ em um fragmento florestal com área aproximada de 5 hectares, 


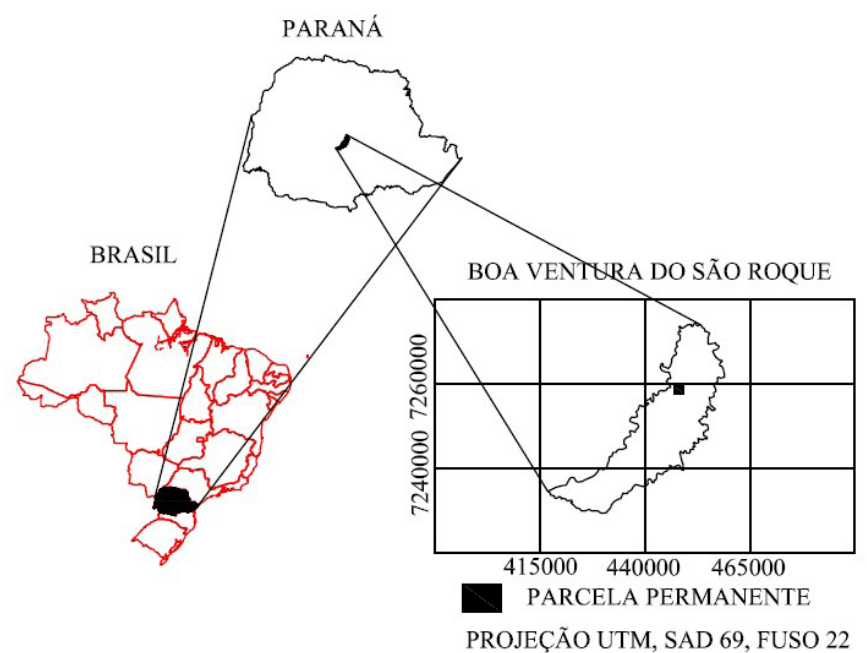

Figura 1. Localização da área de estudo em Boa Ventura do São Roque (PR). FONTE: adaptado de IBGE, 2011. Figure 1. Survey area location in Boa Ventura do São Roque - PR. SOURCE: Adapted from IBGE, 2011.

a qual foi dividida em 50 subunidades contíguas de $100 \mathrm{~m}^{2}(10 \times 10 \mathrm{~m})$. A dinâmica florestal foi obtida por meio de duas avaliações, no intervalo de dois anos, sendo estas realizadas em 2007 e 2009.

Nos dois períodos de avaliação (2007 e 2009), foram medidas as circunferências a $1,30 \mathrm{~m}$ do solo em todas as árvores com DAP $\geq 5 \mathrm{~cm}$, sendo estas numeradas com etiquetas de metal à altura de 1,30 m do solo. A identificação taxonômica das espécies foi realizada inicialmente em campo, segundo características dendrológicas e, posteriormente, em laboratório, de acordo com a nomenclatura do Angiosperm Phylogeny Group III (APG III, 2009).

Para representar os índices fitossociológicos da estrutura horizontal, os parâmetros avaliados foram: densidade absoluta (DA), densidade relativa (DR), dominância absoluta (DoA), dominância relativa (DoR), frequência absoluta (FA), frequência relativa (FR), valor de cobertura (VC) e valor de importância (VI). A riqueza florística arbórea foi estimada pelos índices de Simpson (D) e Shannon (H'), conforme Mueller-Dombois \& Ellenberg (1974).

Para a avaliação da dinâmica da vegetação, foram calculados os indivíduos ingressos, a mortalidade e o crescimento (incremento periódico anual) para cada espécie, bem como para a vegetação. Os indivíduos ingressos correspondem àqueles que durante $2007 \mathrm{e}$ 2009 atingiram $\mathrm{DAP} \geq 5 \mathrm{~cm}$. Mortalidade refere-se ao número de árvores que, na primeira ocasião, estavam vivas, mas, na segunda ocasião, encontravam-se mortas. O incremento periódico anual (IPA) expressa o crescimento anual de um indivíduo e foi obtido pela Equação 1:

$I P A=\frac{\sum_{i=1}^{n}\left(D A P_{2009}-D A P_{2007}\right)}{N}$

Onde:

IPA: incremento periódico anual em diâmetro;

$\mathrm{DAP}_{2009}$ : diâmetro medido a $1,30 \mathrm{~m}$ de altura da i-ésima árvore viva na segunda ocasião, ou seja, 2009;

$\mathrm{DAP}_{2007}$ : diâmetro medido a $1,30 \mathrm{~m}$ de altura da i-ésima árvore viva na primeira ocasião, ou seja, 2007;

$\mathrm{i}=1,2,3, \ldots ., \mathrm{n}$;

$\mathrm{N}$ : número total de anos monitorados.

Para realização dos cálculos dos parâmetros fitossociológicos, distribuição diamétrica e processos dinâmicos (crescimento, mortalidade e ingresso), utilizou-se o software Mata Nativa 2.10 (CIENTEC, 2006).

\section{RESULTADOS E DISCUSSÃO}

\subsection{Levantamentos florístico e fitossociológico}

Os resultados dos levantamentos florísticos e fitossociológico do remanescente florestal estudado em 2007 e 2009 são apresentados nas Tabelas 1 e 2, seguindo a ordenação alfabética das famílias botânicas. 
Tabela 1. Parâmetros fitossociológicos das espécies amostradas no Fragmento de Floresta Ombrófila Mista Montana em 2007.

Table 1. Species Phytosociological parameters sampled in Montane Araucaria Forest Fragment, in 2007.

\begin{tabular}{|c|c|c|c|c|c|c|c|c|c|}
\hline Família/espécies & $\mathbf{N}$ & $\begin{array}{c}\text { DA } \\
\left(\mathbf{N} \cdot \mathbf{h a}^{-1}\right)\end{array}$ & $\begin{array}{l}\text { DR } \\
(\%)\end{array}$ & $\begin{array}{c}\text { DoA } \\
\left(\mathbf{m}^{2} \cdot h \mathbf{a}^{-1}\right)\end{array}$ & $\begin{array}{c}\text { DoR } \\
(\%)\end{array}$ & $\begin{array}{l}\text { FA } \\
(\%)\end{array}$ & $\begin{array}{l}\text { FR } \\
(\%)\end{array}$ & $\begin{array}{l}\text { VC } \\
(\%)\end{array}$ & $\begin{array}{l}\text { VI } \\
(\%)\end{array}$ \\
\hline \multicolumn{10}{|l|}{ Annonaceae } \\
\hline Annona rugulosa & 12 & 24,0 & 0,92 & 0,11 & 0,33 & 10,0 & 1,11 & 0,63 & 0,79 \\
\hline Annona sylvatica & 4 & 8,0 & 0,31 & 0,03 & 0,08 & 2,0 & 0,22 & 0,20 & 0,20 \\
\hline \multicolumn{10}{|l|}{ Aquifoliaceae } \\
\hline Ilex brevicuspis & 29 & 58,0 & 2,23 & 0,38 & 1,15 & 18,0 & 2,00 & 1,69 & 1,79 \\
\hline Ilex theezans & 1 & 2,0 & 0,08 & 0,01 & 0,02 & 2,0 & 0,22 & 0,05 & 0,11 \\
\hline \multicolumn{10}{|l|}{ Arecaceae } \\
\hline Syagrus romanzoffiana & 1 & 2,0 & 0,08 & 0,1 & 0,31 & 2,0 & 0,22 & 0,20 & 0,20 \\
\hline \multicolumn{10}{|l|}{ Asparagaceae } \\
\hline Cordyline spectabilis & 50 & 100,0 & 3,85 & 0,93 & 2,8 & 38,0 & 4,23 & 3,33 & 3,63 \\
\hline \multicolumn{10}{|l|}{ Cannabaceae } \\
\hline Trema micrantha & 1 & 2,0 & 0,08 & 0,01 & 0,02 & 2,0 & 0,22 & 0,05 & 0,11 \\
\hline \multicolumn{10}{|l|}{ Cardiopteridaceae } \\
\hline Citronella paniculata & 1 & 2,0 & 0,08 & 0,01 & 0,02 & 2,0 & 0,22 & 0,05 & 0,11 \\
\hline \multicolumn{10}{|l|}{ Clethraceae } \\
\hline Clethra scabra & 2 & 4,0 & 0,15 & 0,07 & 0,2 & 2,0 & 0,22 & 0,18 & 0,19 \\
\hline \multicolumn{10}{|l|}{ Cyatheaceae } \\
\hline Cyathea sp. & 4 & 8,0 & 0,31 & 0,08 & 0,25 & 6,0 & 0,67 & 0,28 & 0,41 \\
\hline \multicolumn{10}{|l|}{ Dicksoniaceae } \\
\hline Dicksonia sellowiana & 76 & 152,0 & 5,86 & 3,75 & 11,3 & 34,0 & 3,79 & 8,58 & 6,98 \\
\hline \multicolumn{10}{|l|}{ Euphorbiaceae } \\
\hline Manihot grahanii & 10 & 20,0 & 0,77 & 0,08 & 0,25 & 14,0 & 1,56 & 0,51 & 0,9 \\
\hline Sapium glandulosum & 2 & 4,0 & 0,15 & 0,07 & 0,21 & 2,0 & 0,22 & 0,18 & 0,2 \\
\hline Sebastiania commersoniana & 1 & 2,0 & 0,08 & 0,01 & 0,03 & 2,0 & 0,22 & 0,06 & 0,1 \\
\hline \multicolumn{10}{|l|}{ Fabaceae } \\
\hline Albizia polycephala & 26 & 52,0 & 2,00 & 0,18 & 0,54 & 26,0 & 2,90 & 1,27 & 1,8 \\
\hline Anadenanthera colubrina & 136 & 272,0 & 10,5 & 4,56 & 13,7 & 62,0 & 6,90 & 12,1 & 10,4 \\
\hline Bauhinia forficata & 3 & 6,0 & 0,23 & 0,02 & 0,06 & 4,0 & 0,45 & 0,15 & 0,2 \\
\hline Inga sp. & 19 & 38,0 & 1,46 & 0,31 & 0,92 & 24,0 & 2,67 & 1,19 & 1,7 \\
\hline Lonchocarpus cultratus & 43 & 86,0 & 3,31 & 0,41 & 1,24 & 54,0 & 6,01 & 2,28 & 3,5 \\
\hline Lonchocarpus muehlbergianus & 6 & 12,0 & 0,46 & 0,03 & 0,09 & 8,0 & 0,89 & 0,28 & 0,5 \\
\hline Machaerium paraguariense & 38 & 76,0 & 2,93 & 0,59 & 1,78 & 32,0 & 3,56 & 2,36 & 2,8 \\
\hline Machaerium stipitatum & 2 & 4,0 & 0,15 & 0,02 & 0,06 & 2,0 & 0,22 & 0,11 & 0,1 \\
\hline \multicolumn{10}{|l|}{ Lamiaceae } \\
\hline Vitex megapotamica & 11 & 22,0 & 0,85 & 0,14 & 0,43 & 8,0 & 0,89 & 0,64 & 0,7 \\
\hline \multicolumn{10}{|l|}{ Lauraceae } \\
\hline Nectandra lanceolata & 13 & 26,0 & 1 & 0,34 & 1,01 & 14,0 & 1,56 & 1,01 & 1,2 \\
\hline \multicolumn{9}{|l|}{ Lauraceae } & 6,1 \\
\hline Ocotea puberula & 70 & 140,0 & 5,39 & 6,82 & 20,5 & 50,0 & 5,57 & 12,9 & 10,5 \\
\hline $\begin{array}{l}\text { Loganiaceae } \\
\text { Strychnos brasiliensis }\end{array}$ & 3 & 6,0 & 0,23 & 0,02 & 0,05 & 4,0 & 0,45 & 0,14 & 0,2 \\
\hline \multicolumn{10}{|l|}{ Malvaceae } \\
\hline Luehea divaricata & 7 & 14,0 & 0,54 & 0,08 & 0,24 & 14,0 & 1,56 & 0,39 & 0,8 \\
\hline \multicolumn{10}{|l|}{ Meliaceae } \\
\hline Cedrela fissilis & 12 & 24,0 & 0,92 & 0,56 & 1,69 & 18,0 & 2,00 & 1,31 & 1,5 \\
\hline
\end{tabular}

$\mathrm{N}$ : número de indivíduos; DA: densidade absoluta; DR: densidade relativa; DoA: dominância absoluta; DoR: dominância relativa; FA: frequência absoluta; FR: frequência relativa; VC: valor de cobertura; VI: valor de importância. 
Tabela 1. Continuação...

Table 1. Continued...

\begin{tabular}{|c|c|c|c|c|c|c|c|c|c|}
\hline Família/espécies & $\mathbf{N}$ & $\begin{array}{c}\text { DA } \\
\left(\mathbf{N} \cdot \mathbf{h a}^{-1}\right)\end{array}$ & $\begin{array}{l}\text { DR } \\
(\%)\end{array}$ & $\begin{array}{c}\text { DoA } \\
\left(\mathbf{m}^{2} \cdot \mathbf{h a}^{-1}\right)\end{array}$ & $\begin{array}{c}\text { DoR } \\
(\%)\end{array}$ & $\begin{array}{l}\text { FA } \\
(\%)\end{array}$ & $\begin{array}{l}\text { FR } \\
(\%)\end{array}$ & $\begin{array}{l}\text { VC } \\
(\%)\end{array}$ & $\begin{array}{l}\text { VI } \\
(\%)\end{array}$ \\
\hline \multicolumn{10}{|l|}{ Myrtaceae } \\
\hline Campomanesia xanthocarpa & 1 & 2,0 & 0,08 & 0,00 & 0,01 & 2,0 & 0,22 & 0,05 & 0,1 \\
\hline Eugenia pyriformis & 2 & 4,0 & 0,15 & 0,03 & 0,1 & 4,0 & 0,45 & 0,13 & 0,2 \\
\hline Myrcia hatschbachii & 2 & 4,0 & 0,15 & 0,01 & 0,03 & 4,0 & 0,45 & 0,09 & 0,2 \\
\hline \multicolumn{10}{|l|}{ Phytolaccaceae } \\
\hline Phytolacca dioica & 4 & 8,0 & 0,31 & 0,15 & 0,44 & 8,0 & 0,89 & 0,38 & 0,5 \\
\hline \multicolumn{10}{|l|}{ Primulaceae } \\
\hline Myrsine coriacea & 1 & 2,0 & 0,08 & 0,01 & 0,01 & 2,0 & 0,22 & 0,05 & 0,1 \\
\hline Myrsine umbellata & 1 & 2,0 & 0,08 & 0,01 & 0,04 & 2,0 & 0,22 & 0,06 & 0,1 \\
\hline \multicolumn{10}{|l|}{ Rosaceae } \\
\hline Prunus brasiliensis & 4 & 8,0 & 0,31 & 0,15 & 0,45 & 8,0 & 0,89 & 0,38 & 0,6 \\
\hline \multicolumn{10}{|l|}{ Rubiaceae } \\
\hline Coutarea hexandra & 1 & 2,0 & 0,08 & 0,01 & 0,02 & 2,0 & 0,22 & 0,05 & 0,1 \\
\hline \multicolumn{10}{|l|}{ Rutaceae } \\
\hline Zanthoxylum rhoifolium & 23 & 46,0 & 1,77 & 0,25 & 0,74 & 40,0 & 4,45 & 1,26 & 2,3 \\
\hline \multicolumn{10}{|l|}{ Salicaceae } \\
\hline Banara tomentosa & 1 & 2,0 & 0,08 & 0,01 & 0,01 & 2,0 & 0,22 & 0,05 & 0,1 \\
\hline Casearia decandra & 2 & 4,0 & 0,15 & 0,02 & 0,07 & 4,0 & 0,45 & 0,11 & 0,2 \\
\hline \multicolumn{10}{|l|}{ Sapindaceae } \\
\hline Allophylus edulis & 166 & 332,0 & 12,8 & 1,77 & 5,33 & 80,0 & 8,91 & 9,07 & 9,0 \\
\hline Cupania vernalis & 110 & 220,0 & 8,47 & 1,73 & 5,22 & 58,0 & 6,46 & 6,85 & 6,7 \\
\hline Matayba elaeagnoides & 235 & 470,0 & 18 & 4,36 & 13,1 & 88,0 & 9,80 & 15,6 & 13,7 \\
\hline \multicolumn{10}{|l|}{ Solanaceae } \\
\hline Cestrum sp. & 10 & 20,0 & 0,77 & 0,07 & 0,2 & 16,0 & 1,78 & 0,49 & 0,9 \\
\hline \multicolumn{10}{|l|}{ Verbenaceae } \\
\hline Aegiphila integrifolia & 1 & 2,0 & 0,08 & 0,01 & 0,02 & 2,0 & 0,22 & 0,05 & 0,1 \\
\hline Árvores mortas & 62 & 124,0 & 4,78 & 3,45 & 10,4 & 58,0 & 6,46 & 7,59 & 7,2 \\
\hline Total & 1298 & 2596,0 & 21,1 & 33,25 & 100 & 898 & 100 & 100 & 100 \\
\hline
\end{tabular}

N: número de indivíduos; DA: densidade absoluta; DR: densidade relativa; DoA: dominância absoluta; DoR: dominância relativa; FA: frequência absoluta; FR: frequência relativa; VC: valor de cobertura; VI: valor de importância.

Tabela 2. Parâmetros fitossociológicos das espécies amostradas na Floresta Ombrófila Mista Montana, em 2009.

Table 2. Species Phytosociological parameters sampled in Montane Araucaria Forest Fragment, in 2009.

\begin{tabular}{|c|c|c|c|c|c|c|c|c|c|}
\hline Família/espécies & $\mathbf{N}$ & $\begin{array}{c}\text { DA } \\
\left(\mathbf{N} \cdot \mathbf{h a}^{-1}\right)\end{array}$ & $\begin{array}{l}\text { DR } \\
(\%)\end{array}$ & $\begin{array}{c}\text { DoA } \\
\left(\mathbf{m}^{2} \cdot \mathbf{h} \mathbf{a}^{1}\right)\end{array}$ & $\begin{array}{c}\text { DoR } \\
(\%)\end{array}$ & $\begin{array}{l}\text { FA } \\
(\%)\end{array}$ & $\begin{array}{l}\text { FR } \\
(\%)\end{array}$ & $\begin{array}{l}\text { VC } \\
(\%)\end{array}$ & $\begin{array}{c}\text { VI } \\
(\%)\end{array}$ \\
\hline \multicolumn{10}{|l|}{ Annonaceae } \\
\hline Annona rugulosa & 12 & 24 & 0,94 & 0,12 & 0,35 & 10 & 1,13 & 0,64 & 0,8 \\
\hline Annona sylvatica & 5 & 10 & 0,39 & 0,04 & 0,11 & 4 & 0,45 & 0,25 & 0,32 \\
\hline \multicolumn{10}{|l|}{ Aquifoliaceae } \\
\hline Ilex brevicuspis & 29 & 58 & 2,27 & 0,45 & 1,32 & 18 & 2,04 & 1,79 & 1,87 \\
\hline Ilex theezans & 1 & 2 & 0,08 & 0,01 & 0,02 & 2 & 0,23 & 0,05 & 0,11 \\
\hline \multicolumn{10}{|l|}{ Arecaceae } \\
\hline Syagrus romanzoffiana & 1 & 2 & 0,08 & 0,11 & 0,32 & 2 & 0,23 & 0,2 & 0,21 \\
\hline \multicolumn{10}{|l|}{ Asparagaceae } \\
\hline Cordyline spectabilis & 50 & 100 & 3,91 & 0,99 & 2,92 & 38 & 4,3 & 3,42 & 3,71 \\
\hline
\end{tabular}

N: número de indivíduos; DA: densidade absoluta; DR: densidade relativa; DoA: dominância absoluta; DoR: dominância relativa; FA: frequência absoluta; FR: frequência relativa; VC: valor de cobertura; VI: valor de importância. 
Tabela 2. Continuação...

Table 2. Continued...

$\begin{array}{llclllllll}\text { Família/espécies } & \mathbf{N} & \begin{array}{c}\text { DA } \\ \left(\mathbf{N} \cdot h a^{-1}\right)\end{array} & \begin{array}{c}\text { DR } \\ (\%)\end{array} & \begin{array}{c}\text { DoA } \\ \left(\mathrm{m}^{2} \cdot \mathrm{ha}^{1}\right)\end{array} & \begin{array}{c}\text { DoR } \\ (\%)\end{array} & \begin{array}{c}\text { FA } \\ (\%)\end{array} & \begin{array}{c}\text { FR } \\ (\%)\end{array} & \begin{array}{c}\text { VC } \\ (\%)\end{array} & \begin{array}{c}\text { VI } \\ (\%)\end{array}\end{array}$

\section{Cannabaceae}

Trema micrantha

$\begin{array}{lccccccccc}\text { Trema micrantha } & 1 & 2 & 0,08 & 0,01 & 0,02 & 2 & 0,23 & 0,05 & 0,11 \\ \begin{array}{l}\text { Cardiopteridaceae } \\ \text { Citronella paniculata }\end{array} & 1 & 2 & 0,08 & 0,01 & 0,02 & 2 & 0,23 & 0,05 & 0,11 \\ \begin{array}{l}\text { Clethraceae } \\ \text { Clethra scabra }\end{array} & 2 & 4 & 0,16 & 0,08 & 0,24 & 2 & 0,23 & 0,2 & 0,21\end{array}$

Cardiopteridaceae

$\begin{array}{llllllllll}\text { Clethra scabra } & 2 & 4 & 0,16 & 0,08 & 0,24 & 2 & 0,23 & 0,2 & 0,21 \\ \text { Cunoniaceae } & & & & & & & & & \end{array}$

$\begin{array}{llllllllll}\text { Lamanonia ternata } & 2 & 4 & 0,16 & 0,02 & 0,06 & 4 & 0,45 & 0,11 & 0,22 \\ \text { Cyatheaceae } & & & & & & & & & \end{array}$

$\begin{array}{lllllllllll}\text { Cyathea sp. } & 6 & 12 & 0,47 & 0,14 & 0,41 & 8 & 0,9 & 0,44 & 0,59\end{array}$

\section{Dicksoniaceae}

\begin{tabular}{|c|c|c|c|c|c|c|c|c|c|}
\hline Dicksonia sellowiana & 82 & 164 & 6,41 & 3,84 & 11,3 & 38 & 4,3 & 8,88 & 7,36 \\
\hline \multicolumn{10}{|l|}{ Euphorbiaceae } \\
\hline Manihot grahanii & 10 & 20 & 0,78 & 0,08 & 0,24 & 14 & 1,58 & 0,51 & 0,87 \\
\hline Sapium glandulosum & 2 & 4 & 0,16 & 0,08 & 0,23 & 2 & 0,23 & 0,19 & 0,2 \\
\hline Sebastiania commersoniana & 1 & 2 & 0,08 & 0,01 & 0,04 & 2 & 0,23 & 0,06 & 0,11 \\
\hline \multicolumn{10}{|l|}{ Fabaceae } \\
\hline Albizia polycephala & 26 & 52 & 2,03 & 0,21 & 0,61 & 26 & 2,94 & 1,32 & 1,86 \\
\hline Anadenanthera colubrina & 141 & 282 & 11 & 5,39 & 15,94 & 66 & 7,47 & 13,48 & 11,48 \\
\hline Apuleia leiocarpa & 1 & 2 & 0,08 & 0 & 0,01 & 2 & 0,23 & 0,05 & 0,11 \\
\hline Bauhinia forficata & 7 & 14 & 0,55 & 0,08 & 0,24 & 12 & 1,36 & 0,39 & 0,72 \\
\hline Inga sp. & 19 & 38 & 1,49 & 0,34 & 1 & 24 & 2,71 & 1,24 & 1,73 \\
\hline Lonchocarpus cultratus & 43 & 86 & 3,36 & 0,47 & 1,39 & 54 & 6,11 & 2,37 & 3,62 \\
\hline Lonchocarpus muehlbergianus & 6 & 12 & 0,47 & 0,03 & 0,09 & 8 & 0,9 & 0,28 & 0,49 \\
\hline Machaerium paraguariense & 38 & 76 & 2,97 & 0,65 & 1,92 & 32 & 3,62 & 2,45 & 2,84 \\
\hline Machaerium stipitatum & 2 & 4 & 0,16 & 0,03 & 0,08 & 2 & 0,23 & 0,12 & 0,15 \\
\hline \multicolumn{10}{|l|}{ Lamiaceae } \\
\hline Vitex megapotamica & 11 & 22 & 0,86 & 0,13 & 0,38 & 8 & 0,9 & 0,62 & 0,71 \\
\hline \multicolumn{10}{|l|}{ Lauraceae } \\
\hline Nectandra lanceolata & 13 & 26 & 1,02 & 0,39 & 1,16 & 14 & 1,58 & 1,09 & 1,25 \\
\hline Nectandra megapotamica & 94 & 188 & 7,35 & 1,93 & 5,7 & 64 & 7,24 & 6,53 & 6,76 \\
\hline Ocotea puberula & 70 & 140 & 5,47 & 7,3 & 21,6 & 50 & 5,66 & 13,53 & 10,91 \\
\hline \multicolumn{10}{|l|}{ Loganiaceae } \\
\hline Strychnos brasiliensis & 3 & 6 & 0,23 & 0,02 & 0,05 & 4 & 0,45 & 0,14 & 0,25 \\
\hline \multicolumn{10}{|l|}{ Malvaceae } \\
\hline Luehea divaricata & 8 & 16 & 0,63 & 0,11 & 0,32 & 14 & 1,58 & 0,47 & 0,84 \\
\hline \multicolumn{10}{|l|}{ Meliaceae } \\
\hline Cedrela fissilis & 12 & 24 & 0,94 & 0,68 & 2,01 & 18 & 2,04 & 1,48 & 1,66 \\
\hline \multicolumn{10}{|l|}{ Myrtaceae } \\
\hline Campomanesia xanthocarpa & 2 & 4 & 0,16 & 0,04 & 0,11 & 4 & 0,45 & 0,13 & 0,24 \\
\hline Eugenia pyriformis & 2 & 4 & 0,16 & 0,04 & 0,12 & 4 & 0,45 & 0,14 & 0,24 \\
\hline Myrcia hatschbachii & 2 & 4 & 0,16 & 0,01 & 0,03 & 4 & 0,45 & 0,09 & 0,21 \\
\hline \multicolumn{10}{|l|}{ Phytolaccaceae } \\
\hline Phytolacca dioica & 6 & 12 & 0,47 & 0,23 & 0,67 & 12 & 1,36 & 0,57 & 0,83 \\
\hline \multicolumn{10}{|l|}{ Primulaceae } \\
\hline Myrsine coriacea & 1 & 2 & 0,08 & 0,01 & 0,01 & 2 & 0,23 & 0,05 & 0,11 \\
\hline
\end{tabular}

N: número de indivíduos; DA: densidade absoluta; DR: densidade relativa; DoA: dominância absoluta; DoR: dominância relativa; FA: frequência absoluta; FR: frequência relativa; VC: valor de cobertura; VI: valor de importância. 
Tabela 2. Continuação...

Table 2. Continued...

\begin{tabular}{|c|c|c|c|c|c|c|c|c|c|}
\hline Família/espécies & $\mathbf{N}$ & $\begin{array}{c}\text { DA } \\
\left(\mathbf{N} \cdot \mathbf{h a}^{-1}\right)\end{array}$ & $\begin{array}{l}\text { DR } \\
(\%)\end{array}$ & $\begin{array}{c}\text { DoA } \\
\left(\mathbf{m}^{2} \cdot \mathbf{h} \mathbf{a}^{1}\right)\end{array}$ & $\begin{array}{c}\text { DoR } \\
(\%)\end{array}$ & $\begin{array}{l}\text { FA } \\
(\%)\end{array}$ & $\begin{array}{l}\text { FR } \\
(\%)\end{array}$ & $\begin{array}{l}\text { VC } \\
(\%)\end{array}$ & $\begin{array}{l}\text { VI } \\
(\%)\end{array}$ \\
\hline Myrsine umbellata & 1 & 2 & 0,08 & 0,01 & 0,04 & 2 & 0,23 & 0,06 & 0,11 \\
\hline \multicolumn{10}{|l|}{ Rosaceae } \\
\hline Prunus brasiliensis & 4 & 8 & 0,31 & 0,17 & 0,49 & 8 & 0,9 & 0,4 & 0,57 \\
\hline \multicolumn{10}{|l|}{ Rubiaceae } \\
\hline Coutarea hexandra & 1 & 2 & 0,08 & 0,01 & 0,02 & 2 & 0,23 & 0,05 & 0,11 \\
\hline \multicolumn{10}{|l|}{ Rutaceae } \\
\hline Zanthoxylum rhoifolium & 23 & 46 & 1,8 & 0,27 & 0,81 & 40 & 4,52 & 1,3 & 2,38 \\
\hline \multicolumn{10}{|l|}{ Salicaceae } \\
\hline Banara tomentosa & 1 & 2 & 0,08 & 0,01 & 0,01 & 2 & 0,23 & 0,05 & 0,11 \\
\hline Casearia decandra & 2 & 4 & 0,16 & 0,03 & 0,09 & 4 & 0,45 & 0,13 & 0,23 \\
\hline \multicolumn{10}{|l|}{ Salicaceae } \\
\hline Allophylus edulis & 171 & 342 & 13,4 & 2,19 & 6,48 & 86 & 9,73 & 9,93 & 9,86 \\
\hline Cupania vernalis & 111 & 222 & 8,68 & 2,09 & 6,17 & 60 & 6,79 & 7,43 & 7,21 \\
\hline Matayba elaeagnoides & 241 & 482 & 18,8 & 4,91 & 14,5 & 88 & 9,95 & 16,7 & 14,4 \\
\hline \multicolumn{10}{|l|}{ Solanaceae } \\
\hline Cestrum sp. & 11 & 22 & 0,86 & 0,08 & 0,23 & 18 & 2,04 & 0,55 & 1,04 \\
\hline \multicolumn{10}{|l|}{ Verbenaceae } \\
\hline Aegiphila integrifolia & 1 & 2 & 0,08 & 0,01 & 0,02 & 2 & 0,23 & 0,05 & 0,11 \\
\hline Total & 1279 & 2558 & 67,5 & 33,82 & 1754 & 884 & 100 & 100 & 100 \\
\hline
\end{tabular}

N: número de indivíduos; DA: densidade absoluta; DR: densidade relativa; DoA: dominância absoluta; DoR: dominância relativa; FA: frequência absoluta; FR: frequência relativa; VC: valor de cobertura; VI: valor de importância.

A densidade e a composição florística da Floresta Ombrófila Mista Montana estudada sofreram alterações durante o período de 2007 a 2009, de forma que em 2007 foram encontrados 2.596 ind.ha $^{-1}$, distribuídos entre 25 famílias, 40 gêneros e 45 espécies arbóreas, enquanto, em 2009, esse número reduziu ligeiramente para 2.558 ind.ha $^{-1}$, encontrando-se em 27 famílias, 41 gêneros e 47 espécies, representando um pequeno aumento na riqueza florística. As duas novas espécies identificadas em 2009 foram Apuleia leiocarpa e Lamanonia ternata, não tendo sido observada a exclusão de nenhuma espécie em nenhum dos dois levantamentos.

Analisando mais de vinte estudos em parcelas permanentes em remanescentes de Floresta Ombrófila Mista, Figueiredo et al. (2010) afirmam que nessa tipologia florestal, em média, ocorrem em torno de 655 árvores por hectare, representadas por 88 espécies, 59 gêneros e 35 famílias.

Mognon et al. (2012), em levantamentos realizados entre 1999 e 2009, em um fragmento de FOM em General Carneiro (PR), observaram que a densidade absoluta em 1999 foi de 629,25 ind.ha-1 e passou para 629,50 ind. ha $^{-1}$ em 2009. Os autores também registraram aumento da composição florística em 2009, com a inclusão de três espécies e uma família, totalizando 53 espécies e 25 famílias ao longo dos dois períodos estudados.

Em um fragmento de Floresta Ombrófila Mista antropizada, localizado em Guarapuava (PR), Silvestre et al. (2012) contabilizaram 1.114 ind.ha $^{-1}$, distribuídos em 65 espécies, 49 gêneros e 31 famílias. Denota-se a diferença estrutural entre esses resultados e os do presente estudo, pois, embora o número de indivíduos seja mais elevado quando comparado ao de Boa Ventura do São Roque (PR), o estudo realizado em Guarapuava (PR) apresentou maior diversidade de espécies, sendo estas distribuídas em um maior número de gêneros e famílias.

Em relação à riqueza de espécies, as famílias de maior destaque foram: Fabaceae (8), Euphorbiaceae, Lauraceae (3), Myrtaceae (3) e Sapindaceae (3), Annonaceae, Aquifoliaceae (2), Lamiaceae (2), Myrsinaceae (2) e Salicaceae (2), enquanto as demais famílias apresentaram apenas uma espécie.

Um fato observado é que as principais espécies características e de grande potencial econômico da 
Floresta Ombrófila Mista, como a Araucaria angustifolia (pinheiro-do-paraná), Ocotea porosa (imbuia) e Ilex paraguariensis (erva-mate), não ocorrem na área de estudo. Esse aspecto pode estar relacionado à exploração florestal desordenada ocorrida no passado ou mesmo pelo município estar localizado próximo a uma zona ecotonal com a Floresta Estacional Semidecidual. De modo geral, os índices fitossociológicos indicam que não ocorreram mudanças relevantes no período compreendido entre 2007 e 2009.

Resultados semelhantes foram encontrados por Silvestre et al. (2012), nos quais foi observada maior riqueza de espécies para as famílias Fabaceae (7), Lauraceae (6) e Sapindaceae (5), mas com baixo número de espécies de famílias representativas da FOM, como Myrtaceae e Lauraceae.

Conforme os parâmetros fitossociológicos calculados para os períodos de amostragem de 2007 e 2009, Matayba elaeagnoides manteve-se como a espécie mais importante do fragmento por sua alta densidade no local, seguida de Anadenanthera colubrina, que aparece no final do segundo período de avaliação como a segunda espécie mais importante, devido ao ingresso de mais quatro indivíduos da espécie.

A elevada taxa de indivíduos mortos pode ser explicada pela fase de sucessão em que a floresta se encontra, onde espécies iniciais que permaneciam sob o dossel acabaram sendo eliminadas ou substituídas por espécies esciófitas.

Na avaliação de 2009, a espécie Matayba elaeagnoides manteve-se como a de maior valor de importância, seguida das espécies Anaderanthera colubrina e Ocotea puberula, que inverteram sua posição no VI nos dois anos estudados, além de Allophylus edulis, que permaneceu com o quarto maior VI. A espécie Dicksonia sellowiana, embora não classificada como uma árvore, e sim como um feto arbóreo, representou a quinta posição no valor de importância.

O resultado corrobora o observado por Formento et al. (2004) em uma floresta primária alterada, situada no município de Campo Belo do Sul (SC), no qual esses autores verificaram, dentre as cinco espécies com maior VI, que Matayba elaeagnoides e Ocotea puberula apresentaram maior aumento na sua participação no valor de importância, de mesmo modo que nesse estudo.

Nos demais parâmetros fitossociológicos (Tabelas 1 e 2), foi possível verificar que a espécie Matayba elaeagnoides ocupou os maiores valores em densidade, frequência e valor de cobertura, porém, quanto ao parâmetro dominância, o qual representa a soma das áreas basais, a espécie Ocotea puberula obteve os maiores valores. Analisando a mesma tipologia florestal no município de Irati (PR), Valério et al. (2008) encontraram resultados semelhantes quanto aos maiores índices de dominância, destacando a Ocotea puberula em relação às demais espécies de maior VI.

A riqueza florística estimada pelo Índice de Shannon (H') apresentou redução de 2,83 para 2,80, respectivamente, para as avaliações realizadas em 2007 e 2009. A riqueza florística do fragmento estudado pode ser considerada moderada, pois, de acordo com Durigan (1999), os valores desse índice situam-se entre 1,50 e 3,50 para a Floresta Ombrófila Mista e raramente ultrapassam o valor de 4,50 nas demais unidades fitogeográficas.

O Índice de Simpson (C) calculado foi de 0,91 tanto para 2007 como 2009. Esse valor pode considerado alto, por sua proximidade ao valor 1 indicar menor probabilidade de dois indivíduos selecionados ao acaso na amostra pertencerem à mesma espécie. Logo, sugere-se maior heterogeneidade florística e apenas $9 \%$ de chances de ocorrer dominância por alguma espécie no fragmento. Durigan (1999) obteve valores de 0,95 para o Índice de Dominância de Simpson em um fragmento semelhante de mesma tipologia florestal.

Os indivíduos amostrados no período de avaliação foram distribuídos em nove classes de diâmetro, as quais estão representadas na Figura 2, onde se pode observar o formato de "J" invertido, comportamento característico das florestas multiâneas, padrão também observado em outros estudos de Floresta Ombrófila Mista, como de Valério et al. (2008), Figueiredo et al. (2010), Rode et al. (2010), com DAP de inclusão $\geq 10 \mathrm{~cm}$, no Paraná.

Entretanto, para Schaaf et al. (2006), uma grande quantidade de indivíduos de uma determinada espécie nas classes de menor diâmetro nem sempre garante sua presença na estrutura futura de uma floresta. Segundo esses autores, um fator preponderante na presença de determinada espécie na estrutura futura da floresta é a sua capacidade de sobreviver à competição, podendo uma espécie que possui poucos indivíduos nas classes inferiores, mas pequena probabilidade de morrer devido à competição, manter-se na floresta, enquanto 
uma espécie na qual grande parte dos indivíduos seja suscetível à competição necessitar apresentar grande frequência nas classes diamétricas inferiores, para obter algum êxito de sobreviver na comunidade futura.

\subsection{Dinâmica florestal no fragmento avaliado}

Durante o período de monitoramento, foi registrada uma taxa de ingresso de $1,75 \%$, enquanto a taxa de mortalidade foi de $0,41 \%$ ao ano, com incremento periódico anual médio das espécies de $0,32 \mathrm{~cm} \cdot \mathrm{ano}^{-1}$, considerando indivíduos com DAP $\geq 5 \mathrm{~cm}$. Em um fragmento de Floresta Ombrófila Mista no Norte de Santa Catarina, Cubas (2011) registrou taxa média de mortalidade de $2,14 \%$, pouco superior à taxa de ingresso, que foi de 2,01\%, com um incremento periódico anual médio de $0,27 \mathrm{~cm} . \mathrm{ano}^{-1}$.

Lingner et al. (2007) obtiveram os valores de ingresso $(1,9 \%)$, mortalidade $(5,9 \%)$ e incremento médio anual de $1,9 \mathrm{~cm}$.ano ${ }^{-1}$, no monitoramento de três anos, de um fragmento de FOM, em Caçador, Santa Catarina. Em estudos na Floresta Nacional de Irati, no período de 2002, 2005 e 2008, Figueiredo et al. (2010) encontraram taxa de ingresso próximo a 3\%, mortalidade entre $1 \%$ e $2 \%$ e incremento médio anual em torno de $0,21 \mathrm{~cm} . \mathrm{ano}^{-1}$.

A Tabela 3 indica que os maiores incrementos foram observados entre as classes diamétricas de 27,5 a 42,5 cm, com valores variando de 0,57 e 2,13 cm.ano ${ }^{-1}$,

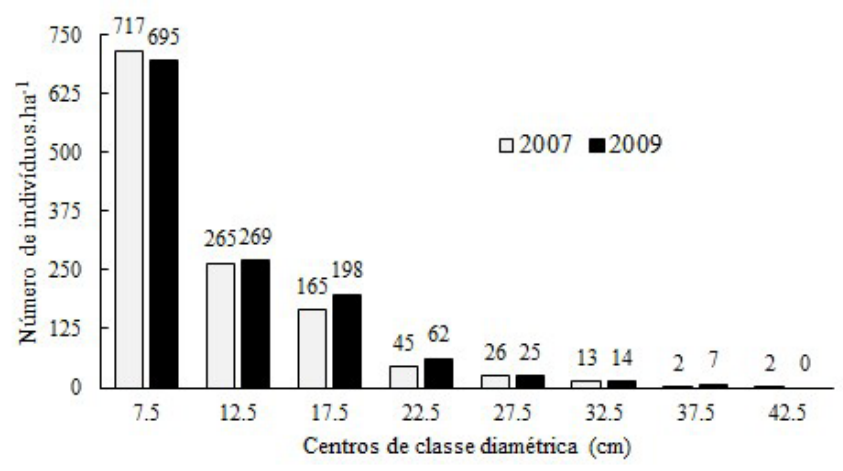

Figura 2. Distribuição diamétrica no período de monitoramento em 2007 e 2009 em Fragmento de Floresta Ombrófila Mista Montana Antropizada.

Figure 2. Diameter distribution in the monitoring period of 2007 and 2009 in an Anthropized Montane Araucaria Forest fragment. Tabela 1. Parâmetros fitossociológicos das espécies amostradas no Fragmento de Floresta Ombrófila Mista Montana em 2007.

Tabela 3. Incremento periódico anual (IPA) das espécies amostradas em ordem decrescente, em Fragmento de Floresta Ombrófila Mista Montana.

Table 3. Periodic Annual Increment (PAI) of species sampled in descending order, in a Montane Araucaria Forest fragment.

\begin{tabular}{|c|c|c|c|c|c|c|c|c|c|c|}
\hline \multirow{2}{*}{ Nome científico } & \multicolumn{9}{|c|}{ Centros de classe diamétrica $(\mathrm{cm})$} & \multirow{2}{*}{$\begin{array}{l}\text { IPA } \\
(\mathrm{cm})\end{array}$} \\
\hline & 7,5 & 12,5 & 17,5 & 22,5 & 27,5 & 32,5 & 37,5 & 42,5 & 47,5 & \\
\hline Casearia decandra & 0,67 & & & & & & & & & 0,670 \\
\hline Clethra scabra & 0,175 & & 1,050 & & & & & & & 0,613 \\
\hline Phytolacca dioica & 0,285 & & & & 2,065 & & & & & 0,588 \\
\hline Cedrela fissilis & 0,286 & 0,018 & & 1,005 & 1,260 & & & 2,565 & & 0,572 \\
\hline Anadenanthera columbrina & 0,285 & 0,609 & 0,868 & 0,783 & 0,830 & 0,890 & 0,748 & & & 0,557 \\
\hline Nectandra megapotamica & 0,420 & 0,732 & 0,923 & & & & & & & 0,553 \\
\hline Luehea divaricata & 0,280 & 1,083 & & & & & & & & 0,509 \\
\hline Machaerium stipitatum & 0,065 & 0,86 & & & & & & & & 0,462 \\
\hline Nectandra lanceolata & 0,051 & 0,563 & 0,763 & 1,035 & & & & & & 0,448 \\
\hline Eugenia pyriformis & 0,320 & 0,56 & & & & & & & & 0,44 \\
\hline
\end{tabular}

IPA: Incremento periódico anual. 
Tabela 3. Continuação...

Table 3. Continued...

\begin{tabular}{|c|c|c|c|c|c|c|c|c|c|c|}
\hline \multirow{2}{*}{ Nome científico } & \multicolumn{9}{|c|}{ Centros de classe diamétrica $(\mathrm{cm})$} & \multirow{2}{*}{$\begin{array}{l}\text { IPA } \\
(\mathrm{cm})\end{array}$} \\
\hline & 7,5 & 12,5 & 17,5 & 22,5 & 27,5 & 32,5 & 37,5 & 42,5 & 47,5 & \\
\hline Sebastiania commersoniana & 0,430 & & & & & & & & & 0,43 \\
\hline Ocotea puberula & & 0,298 & 0,169 & 0,338 & 0,363 & 0,836 & & 1,685 & & 0,419 \\
\hline Cupania vernalis & 0,255 & 0,596 & 0,908 & & & & & & & 0,408 \\
\hline Coutarea hexandra & 0,395 & & & & & & & & & 0,395 \\
\hline Bauhinia forficata & 0,367 & & & & & & & & & 0,367 \\
\hline Allophylus edulis & 0,309 & 0,518 & & & & & & & & 0,339 \\
\hline Vitex megapotamica & 0,2 & 0,493 & & & & & & & & 0,298 \\
\hline Sapium glandulosum & & 0,16 & 0,400 & & & & & & & 0,28 \\
\hline Matayba elaeagnoides & 0,131 & 0,386 & 0,537 & 0,567 & 0,845 & & & & & 0,264 \\
\hline Syagrus romanzoffiana & & & & & 0,255 & & & & & 0,255 \\
\hline Ilex brevicuspis & 0,092 & 0,658 & 1,400 & & & & & & & 0,254 \\
\hline Inga sp. & 0,145 & 0,396 & & & & & & & & 0,23 \\
\hline Lonchocarpus cultratus & 0,183 & 0,442 & 0,670 & & & & & & & 0,225 \\
\hline Prunus brasiliensis & 0,033 & 0,010 & & & 0,800 & & & & & 0,219 \\
\hline Albizia polycephala & 0,172 & 0,800 & & & & & & & & 0,196 \\
\hline Strychnos brasiliensis & 0,187 & & & & & & & & & 0,187 \\
\hline Machaerium paraguariense & 0,080 & 0,418 & 0,700 & & & & & & & 0,185 \\
\hline Zanthoxylum rhoifolium & 0,132 & 0,318 & 0,700 & & & & & & & 0,181 \\
\hline Cestrum sp. & 0,174 & & & & & & & & & 0,174 \\
\hline Cordyline spectabilis & 0,125 & 0,217 & & & & & & & & 0,164 \\
\hline Cyathea sp. & 0,08 & 0,445 & & & & & & & & 0,151 \\
\hline Myrsine coriacea & 0,145 & & & & & & & & & 0,145 \\
\hline Myrcia hatschbachii & 0,135 & & & & & & & & & 0,135 \\
\hline Campomanesia xanthocarpa & 0,125 & & & & & & & & & 0,125 \\
\hline Manihot grahamii & 0,121 & & & & & & & & & 0,121 \\
\hline Annona rugulosa & 0,129 & & & & & & & & & 0,118 \\
\hline Citronella paniculata & 0,080 & & & & & & & & & 0,080 \\
\hline Lonchocarpus muehlbergianus & 0,079 & & & & & & & & & 0,079 \\
\hline Annona sylvatica & 0,076 & & & & & & & & & 0,076 \\
\hline Dicksonia sellowiana & & 0,020 & 0,076 & 0,013 & & & & & & 0,068 \\
\hline Ilex theezans & 0,050 & & & & & & & & & 0,050 \\
\hline Trema micrantha & 0,050 & & & & & & & & & 0,050 \\
\hline Aegiphila integrifolia & 0,045 & & & & & & & & & 0,045 \\
\hline Myrsine umbellata & & & & & & & & & & 0,000 \\
\hline Banara tomentosa & & & & & & & & & & 0,000 \\
\hline Média & 0,219 & 0,471 & 0,435 & 0,452 & 0,566 & 0,84 & 0,748 & 2,125 & & 0,328 \\
\hline
\end{tabular}

IPA: Incremento periódico anual.

respectivamente. Dentre as espécies, o maior IPA médio verificado foi referente à Casearia decandra $\left(0,67 \mathrm{~cm}^{-a n o}{ }^{-1}\right)$, apenas encontrada no menor centro de classe, seguida de Clethra scabra $\left(0,61 \mathrm{~cm}^{-a n o^{-1}}\right)$, com incrementos nas classes de $7,5 \mathrm{~cm}$ e $17,5 \mathrm{~cm}$, e Phytolacca dioica $\left(0,59 \mathrm{~cm}^{\mathrm{ano}} \mathrm{o}^{-1}\right)$ em duas classes. A espécie Anadenanthera colubrina obteve incremento em todas as classes de diâmetro, exceto nas classes de
$42,5 \mathrm{~cm}$ e 47,5 cm, nas quais não possuía indivíduos representados.

No entanto, as espécies Myrsine umbellata e Banara tomentosa não sofreram alteração em seu crescimento. A espécie Cedrela fissilis registrou incremento superior ao da maioria das demais espécies encontradas nessa tipologia florestal e superior aos resultados de Schaaf et al. (2005) e Mattos et al. (2010), os quais 
observaram incremento médio anual do diâmetro da espécie de 0,4 cm.ano ${ }^{-1}$.

\section{CONCLUSÕES}

Com base na florística, estrutura e dinâmica da Floresta Ombrófila Mista Montana Antropizada, conclui-se que:

- a família Fabaceae apresentou oito espécies, sendo esta a família de maior riqueza do fragmento estudado;

- a espécie Matayba elaeagnoides apresentou maior densidade e frequência, com o maior Valor de Importância no remanescente florestal analisado;

- Casearia decandra, Clethra scabra e Phytolacca dioica apresentaram os maiores valores de incremento periódico annual;

- Com base nos parâmetros de IPA e na taxa superior de ingresso de indivíduos em relação à mortalidade e aos índices de diversidade considerados moderadamente altos, conclui-se que o fragmento estudado encontra-se em processo contínuo de sucessão.

\section{STATUS DA SUBMISSÃO}

Recebido: 19 maio, 2014

Aceito: 27 jul., 2016

\section{AUTOR(ES) PARA CORRESPONDÊNCIA}

\section{Joelmir Augustinho Mazon}

Laboratório de Ciências Florestais e Forrageiras, Universidade Estadual do Centro Oeste UNICENTRO, Rua Simeão Camargo Varela de Sá, 3, Vila Carli, CEP 85040-080, Guarapuava, PR, Brasil e-mail: joelmir23@hotmail.com

\section{REFERENNCIAS}

Angiosperm Phylogeny Group - APG III. An update of the Angiosperm Phylogeny Group classification for the orders and families of flowering plants: APG III. Botanical Journal of the Linnean Society 2009; 161(2): 105-121. http:// dx.doi.org/10.1111/j.1095-8339.2009.00996.x.

Castella PR, Britez RM. A floresta com araucária no Paraná: conservação e diagnóstico dos remanescentes florestais. Brasília: Ministério do Meio Ambiente; 2004.
Consultoria e Desenvolvimento de Sistemas Ltda - CIENTEC. Mata Nativa 2: sistema para análise fitossociológica e elaboração de inventários e planos de manejo de florestas nativas [software]. Viçosa; 2006.

Cubas R. Florística, estrutura e dinâmica em uma Floresta ombrófila mista no norte do estado de Santa Catarina [dissertação]. Irati: Universidade Estadual do Centro Oeste; 2011.

Durigan ME. Florística, dinâmica e análise protéica de uma Floresta Ombrófila Mista em São João do Triunfo - PR [dissertação]. Curitiba: Universidade Federal do Paraná; 1999.

Empresa Brasileira de Pesquisa Agropecuária - EMBRAPA. Sistema brasileiro de classificação de solos. 2. ed. Rio de Janeiro; 2006.

Figueiredo A Fo, Dias AN, Stepka TF, Sawczuk AR. Crescimento, mortalidade, ingresso e distribuição diamétrica em Floresta Ombrófila Mista. Revista Floresta 2010; 40(4): 763-776

Formento S, Schorn LA, Ramos RAB. Dinâmica estrutura arbórea de uma floresta Ombrófila Mista em Campo Belo do Sul, SC. Cerne 2004; 10(2): 196-212.

Instituto Brasileiro de Geografia e Estatística - IBGE. Manual técnico da vegetação brasileira. 2 . ed. Rio de Janeiro; 2012.

Leite PF. As diferentes unidades fitoecológicas da Região Sul do Brasil: proposta de classificação [tese]. Curitiba: Universidade Federal do Paraná; 1994.

Lingner DV, Oliveira YMMD, Rosot NC, Dlugosz FL. Caracterização da estrutura e da dinâmica de um remanescente de floresta de araucária no Planalto Catarinense. Pesquisa Florestal Brasileira 2007; 55: 55-66.

Mattos PP, Oliveira MF, Agustini AF, Braz EM, Rivera $\mathrm{H}$, Oliveira YMM et al. Aceleração do crescimento em diâmetro de espécies da floresta Ombrófila Mista nos últimos 90 anos. Pesquisa Florestal Brasileira 2010; 30(64): 319-326. http://dx.doi.org/10.4336/2010.pfb.30.64.319.

Medeiros JD, Savi M, Brito BFA. Seleção de áreas para criação de unidades de conservação na Floresta Ombrófila Mista. Biotemas 2005; 18(2): 33-50.

Mognon F, Dallagnol F, Sanquetta CR, Corte AP, Maas G. Uma década de dinâmica florística e fitossociológica em Floresta Ombrófila Mista Montana no sul do Paraná. Revista de Estudos Ambientais 2012; 14(1): 43-59.

Moscovich FA. Dinâmica de crescimento de uma Floresta Ombrófila Mista em Nova Prata, RS [tese]. Santa Maria: Universidade Federal de Santa Maria; 2006.

Mueller-Dombois D, Ellenberg H. Aims and methods of vegetation ecology. New York: Wiley; 1974.

Rode R, Figueiredo A Fo, Galvão F, Machado SAM. Estrutura horizontal da comunidade arbórea sob um povoamento de Araucaria angustifolia e uma Floresta 
Ombrófila Mista. Pesquisa Florestal Brasileira 2010; 30(64): 347-361. http://dx.doi.org/10.4336/2010.pfb.30.64.347.

Roderjan CV, Galvão F, Kuniyoshi YS, Hatschbach GG. As regiões fitogeográficas do Estado do Paraná. Revista Ciência e Ambiente 2002; 24: 75-92.

Schaaf LB, Figueiredo A Fo, Galvão F, Sanquetta CR. Alteração na estrutura diamétrica de uma Floresta Ombrófila Mista no período entre 1979 e 2000. Revista Árvore 2006; 30(2): 283-295. http://dx.doi.org/10.1590/ S0100-67622006000200016.

Schaaf LB, Figueiredo A Fo, Sanquetta CR, Galvão F. Incremento diamétrico e em área basal no período 19792000 de espécies arbóreas de uma Floresta Ombrófila Mista localizada no sul do Paraná. Floresta 2005; 35(2): 271-290. http://dx.doi.org/10.5380/rf.v35i2.4615.
Silvestre R, Koehler HS, Machado AS, Balbinot R, Watzlawick LF. Análise estrutural e distribuição espacial em remanescente de Floresta Ombrófila Mista, Guarapuava (PR). Revista Ambiência 2012; 8(2): 259-274. http://dx.doi. org/10.5777/ambiencia.2012.02.03.

Thomaz, EL, Vestena, LR. Aspectos Climáticos de Guarapuava-PR. Guarapuava: Editora Unicentro; 2003.

Valério AF, Watzlawick LF, Saueressig D, Puton V, Pimentel A. Análise da composição florística e da estrutura horizontal de uma Floresta Ombrófila Mista Montana, Município de Irati- PR, Brasil. Revista Acadêmica: Ciências Agrárias e Ambientais 2008; 6(2): 137-147.

Whitmore TC. Secondary succession from seed in Tropical Rain Forests. Forestry Abstracts 1983; 44(12): 767-779. 